\title{
Gargle/Nasal Wash Dosage Form
}

National Cancer Institute

\section{Source}

National Cancer Institute. Gargle/Nasal Wash Dosage Form. NCI Thesaurus. Code C149522.

Liquid preparation consisting of a solution intended for use as a gargle or a nasal wash. 